\title{
The impact of alexithymia on autism diagnostic assessments
}

Hannah Hobson ${ }^{\mathrm{a},}{ }^{,}$, Heather Westwood ${ }^{\mathrm{b}}$, Jane Conwayc, Fiona McEwen ${ }^{\mathrm{c}, \mathrm{d}, \mathrm{e}}$, Emma Colvert $^{\mathrm{c}}$, Caroline Catmur ${ }^{f}$, Geoffrey Bird ${ }^{c, g}$, Francesca Happéc,

a Department of Psychology, Social Work \& Counselling, University of Greenwich, Bronte Building, Avery Hill Road, Eltham, London, SE9 2UG, United Kingdom

${ }^{b}$ Psychological Medicine, Institute of Psychiatry, Psychology and Neuroscience, King's College London, London, SE5 8AF, United Kingdom

'Social, Genetic and Developmental Psychiatry Centre, Institute of Psychiatry, Psychology and Neuroscience, King's College London, London, SE5 8AF, United Kingdom

${ }^{\mathrm{d}}$ Biological \& Experimental Psychology, School of Biological \& Chemical Sciences, Queen Mary University of London

${ }^{e}$ Child \& Adolescent Psychiatry, Institute of Psychiatry, Psychology and Neuroscience, King's College London, SE5 8AF, United Kingdom

${ }^{\mathrm{f}}$ Department of Psychology, Institute of Psychiatry, Psychology and Neuroscience, King's College London, London, SE5 8AF, United Kingdom

${ }^{\mathrm{g}}$ Department of Experimental Psychology, University of Oxford, New Radcliffe House, Radcliffe Observatory Quarter, Oxford, OX2 6GG, United Kingdom

*Corresponding author: $\underline{\text { h.hobson@greenwich.ac.uk }}$ 


\begin{abstract}
Alexithymia, a difficulty identifying and communicating one's own emotions, affects socio-emotional processes, such as emotion recognition and empathy. Co-occurring alexithymia is prevalent in Autism Spectrum Disorder (ASD) and underlies some socio-emotional difficulties previously attributed to autism. Socio-emotional abilities are examined during behavioural diagnostic assessments of autism, yet the effect of alexithymia on these assessments is not known. In this study, two previously collected samples of Autism Diagnostic Observation Schedule (ADOS) assessments were used to examine the relationship between alexithymia and ADOS score. Participants included 96 women with anorexia, and 147 adolescents who were either high in autistic symptoms, or whose twin had high autistic symptoms. We examined 1) the impact of alexithymia on meeting the criteria for autism/ASD, 2) correlations between alexithymia and ADOS subscales, and 3) whether alexithymia predicted scores on specific ADOS items, selected a priori based on the literature. In the adolescent group, parent-reported (but not self-reported) alexithymia predicted autism/ASD diagnosis, correlated with both sub-scales, and predicted scores on ADOS items. Fewer associations were observed in the anorexic sample, but the presence of alexithymia predicted a near fourfold increase in the likelihood of meeting diagnostic criteria for autism/ASD in this sample.
\end{abstract}




\section{The impact of alexithymia on autism diagnostic assessments}

Alexithymia, a sub-clinical condition characterised by a difficulty identifying and describing one's own emotional states, is relevant to the understanding and treatment of a number of mental health conditions. Although alexithymia is a dimensional trait that varies across the general population, individuals scoring above established cut-offs on alexithymia measures can be considered "alexithymic", and an increased proportion of alexithymic individuals has been reported in Autism Spectrum Disorder (ASD; hereafter referred to as "autism"), and several other psychiatric and neuropsychiatric conditions such as substance abuse, schizophrenia and eating disorders (Berthoz, Lalanne, Crane, \& Hill, 2013; Pinard, Negrete, Annable, \& Audet, 1996; Schmidt, Jiwany, \& Treasure, 1993; van 't Wout, Aleman, Bermond, \& Kahn, 2007; Westwood, Kerr-Gaffney, Stahl, \& Tchanturia, 2017), as well as in acquired brain damage or neurodegenerative disease (Sturm \& Levenson, 2011; Wood \& Williams, 2007). Alexithymia, or decreased emotional awareness more generally, represents a trans-diagnostic risk factor for worse mental health (Kranzler et al., 2016; Kring, 2008). It has also been shown to impact the success of psychological therapy, and therefore understanding and recognising alexithymia may be helpful in guiding treatment decisions (Ogrodniczuk, Piper, \& Joyce, 2011).

Despite evidence that alexithymia may be relevant to understanding socio-emotional difficulties (such as impaired emotion recognition and empathy) across a broad range of clinical conditions, there has been little attempt to investigate the potential impact of alexithymia on diagnostic practices. We focus here on the potential impact of alexithymia on the diagnosis of autism, but similar arguments could be made for other conditions (e.g. depression).

Recent studies have revealed that alexithymia, rather than autism, is responsible for a number of the socio-emotional difficulties commonly attributed to autism. Studies designed to distinguish the effects of alexithymia and autism demonstrate that problems with emotion recognition, eye contact and empathy are associated with alexithymia, rather than autism (Grynberg, Luminet, Corneille, 
Grèzes, \& Berthoz, 2010; Oakley, Brewer, Bird, \& Catmur, 2016; Shah, Hall, Catmur, \& Bird, 2016;

Bird \& Cook, 2013; Bird, Press \& Richardson, 2011). Importantly, autism and alexithymia are distinct. Although between 40 and $65 \%$ of the autistic ${ }^{1}$ population are thought to be alexithymic (Berthoz \& Hill, 2005; Hill, Berthoz, \& Frith, 2004), a figure significantly above the rate of $10 \%$ observed in the general population (Franz et al., 2008), alexithymia is neither necessary nor sufficient for a diagnosis of autism. There exist autistic individuals with and without alexithymia, and alexithymic individuals who do not meet the diagnostic criteria for autism.

These findings have important implications for diagnostic practice. A key piece of evidence clinicians may draw upon when making a diagnosis of autism is behavioural assessment, most commonly the Autism Diagnostic Observation Schedule (ADOS), now in its second edition (ADOS-2). The ADOS is considered by many to be a 'gold standard' test for the presence of autism, and focuses on the domains of social interaction, communication, imagination and restricted and repetitive behaviour. However, some of the elements of this assessment involve socio-emotional processes known to be associated with alexithymia, including verbal and nonverbal communication of emotions, and recognizing emotions in others. Given recent findings that some socio-emotional impairments previously thought to be the result of autism are actually attributable to alexithymia, it is important to determine the impact that alexithymia has on autism diagnostic assessments.

If it is indeed the case that ADOS scores in part reflect several processes now known to be associated with alexithymia, it could be expected that alexithymic individuals would score higher on ADOS assessments than non-alexithymic individuals (where higher scores are taken to indicate more severe autism symptomatology), and that certain items in the ADOS would be associated with alexithymia. In the extreme, an individual may receive a diagnosis of autism when in fact they simply have a high degree of alexithymic traits (a false positive). Another possibility is that if scores on

\footnotetext{
${ }^{1}$ To respect the wishes of autistic individuals and report the study in line with scientific parlance, we use language preferred by clinical professionals (e.g., 'individuals with autism'), as well as the term 'autistic', a term endorsed by many individuals with ASD (see Kenny et al., 2016).
} 
ADOS assessments are highly confounded by alexithymia, and ADOS cut-off scores were determined in populations of autistic individuals with a high degree of co-occurring alexithymia, then individuals who have autism but low levels of alexithymia may not meet ADOS cut-offs and therefore not receive a diagnosis (a false negative). While diagnosis should not be based on any single instrument, in practice the diagnosis of autism in adults, or where a caregiver cannot provide developmental history, may rely heavily on behavioural assessments including the ADOS. As adult diagnosis of autism becomes increasingly common (see Bastiaansen et al., 2011), examining potential confounds of behavioural assessments for autism may become particularly important. Furthermore, in research, the ADOS is often the only measure administered to confirm diagnosis (Falkmer, Anderson, Falkmer, \& Horlin, 2013).

\subsection{Alexithymia and autism symptomatology}

The ADOS comprises four modules, administered dependent upon the verbal ability and age of the individual. Scoring algorithms for use with the latest edition of the ADOS (ADOS-2) yield two subscale scores for Modules 1 to 3: social affect (SA), and restricted and repetitive behaviours (RRB) (Gotham, Risi, Pickles, \& Lord, 2007). Recently published algorithms also allow these same subscale scores to be derived for Module 4 of the ADOS (Hus \& Lord, 2014) (although clinical diagnostic procedures still rely on the previous subscales of Reciprocal Social Interaction and Communication for this Module). The SA scale includes items such as reciprocal social communication, an understanding of social roles and situations, and appropriate use of facial expression and eye contact. The RRB scale includes use of stereotyped words or phrases, and unusual sensory interests or mannerisms. The symptoms assessed in the ADOS have not been investigated for their association with alexithymia before now. However, based on existing literature, it is possible to predict that alexithymia likely impacts at least a subset of the items included in the ADOS assessment.

\subsubsection{Alexithymia and the social affect ADOS subscale}


For adolescents and adults with good verbal ability, the ADOS includes an item which assesses the ability to communicate one's own emotions. Specifically, individuals are asked to identify times that they felt a given emotion, and to describe what that emotion feels like. This clearly requires an ability that is by definition impaired in alexithymia; identifying and describing one's own emotions. Alexithymia is commonly measured using self-report questionnaires such as the Toronto-Alexithymia Scale (e.g. Parker, Bagby, Taylor, Endler, \& Schmitz, 1993). Individuals scoring highly on this measure strongly disagree with statements such as "I am able to describe my feelings easily", and endorse items like "When I am upset, I do not know if I am sad, frightened, or angry". In addition to this clear conceptual overlap, objective data shows that, when asked similar interview questions to those contained in the ADOS, alexithymic individuals (without autism) produce fewer emotion words, and more null responses ("I don't know"), than individuals with fewer alexithymic traits (Wotschack \& Klann-Delius, 2013). Thus, alexithymic individuals would clearly be expected to score higher (indicating greater impairment) on this ADOS item than those without alexithymia.

The ADOS also assesses whether an individual comments on others' emotions or displays empathy. Although empathy deficits are often assumed in autism, research suggests it is alexithymia rather than autism that predicts reduced empathy (Bird et al., 2010; Bird \& Cook, 2013). In the general population, levels of alexithymia are inversely related to empathy; in addition alexithymic individuals perceive others to be in less pain, report lower scores on empathy questionnaires, and demonstrate atypical neural responses to others' pain compared to non-alexithymic people (Grynberg et al., 2010; Guttman \& Laporte, 2002; Moriguchi et al., 2007). Alexithymic individuals also perform worse than typical individuals on tasks requiring the recognition of emotion from faces (Grynberg et al., 2012; Jongen et al., 2014) and voices (Heaton et al., 2012), and alexithymia, rather than autistic traits, accounts for the difficulties in facial and vocal emotion recognition in the autistic population (Cook, Brewer, Shah, \& Bird, 2013; Heaton et al., 2012). Such deficits would likely lead to a reduced ability to interpret accurately, and presumably a reduced propensity to comment upon, others' 
emotions (Coll et al., 2017). Thus, individuals with alexithymia would likely show more impairment on this section of the ADOS than those without alexithymia.

An ADOS assessor will score individuals based on unusual eye-contact, and whether appropriate facial expressions are directed to the assessor. Eye-tracking investigations have shown that alexithymia, rather than autism symptom severity, predicts fixation of the eye region in autism (although it is autism and not alexithymia that predicts attention to the face; Bird et al., 2011). Production of emotional facial expressions has also been shown to be affected in alexithymic individuals, and reduced emotional expression has been linked to alexithymic traits rather than autistic traits in groups with and without autism (Brewer et al., 2016; McDonald \& Prkachin, 1990; Trevisan, Bowering, \& Birmingham, 2016). Limited or abnormal facial expressions and eye contact may thus be a feature of alexithymia and contribute to higher scores on these ADOS items, increasing the likelihood of a diagnosis.

Insight into typical social situations, considered during an ADOS assessment, examines participants' understanding of issues such as what it means to be a friend versus an acquaintance, and why people might seek romantic relationships. At present there is limited experimental evidence about alexithymic individuals' social insight, per se. Nonetheless, alexithymic individuals experience difficulties in their interpersonal lives, including cold, non-assertive social functioning (Spitzer, Siebel-Jürges, Barnow, Grabe, \& Freyberger, 2005; Vanheule, Desmet, Meganck, \& Bogaerts, 2007), and reduced satisfaction in intimate relationships (Humphreys, Wood, \& Parker, 2009). Alexithymia also impacts social reward (Foulkes, Bird, Gökçen, McCrory, \& Viding, 2015) and the ability to draw typical inferences about others' character (Brewer, Collins, Cook, \& Bird, 2015), which could underpin some of the interpersonal problems reported by alexithymic individuals. Interpersonal difficulties and abnormal social responses could feasibly reflect and/or contribute to atypical insights into social situations and roles as measured by the ADOS.

1.2.2 Alexithymia and the restricted and repetitive behaviours ADOS subscale 
The association between alexithymia and RRBs has received comparably less research interest than social abilities. Nonetheless, alexithymia appears to be related to unusual sensory abilities, both in non-autistic (Kano, Hamaguchi, Itoh, Yanai, \& Fukudo, 2007; Nyklíček \& Vingerhoets, 2000) and autistic populations (Milosavljevic et al., 2016), and is related to hypersensitivity to touch and pain and self-reported sensory processing sensitivity (Liss, Mailloux, \& Erchull, 2008; Nyklicek \& Vingerhoets, 2000; Sivik, 1993). Thus, there may be some overlap between the sensory issues reported in autism and those experienced by individuals with alexithymia, but at present there is limited evidence concerning the rest of the RRB scale.

\subsection{Alexithymia and emotional difficulties outside of the autism spectrum - anorexia nervosa}

Alexithymia does not only co-occur with autism, and it is important to consider the impact of alexithymia on autism assessments in groups for which assessment for co-occurring autism is sometimes indicated. One group that may be of particular interest is individuals with eating disorders, and specifically anorexia nervosa (AN).

Research into socio-emotional functioning in AN is surprisingly recent, and findings have been quite mixed. There have been reports of deficits in recognising emotion from faces (Kucharska-Pietura, Nikolaou, Masiak, \& Treasure, 2004; Zonneville-Bendeck, van Goozen, Cohen-Kettenis, van Elburg, \& van Engeland, 2002), reduced empathy (Morris, Bramham, Smith, \& Tchanturia, 2014), and poor theory of mind (Russell, Schmidt, Doherty, Young, \& Tchanturia, 2009; Tchanturia et al., 2004). Poor social-cognitive functioning may be in part the result of generally diminished cognitive function due to starvation; however, in some cases social difficulties are reported to have begun before the onset of eating disorders (and thus before the effects of malnourishment) (Gillberg \& Råstam, 1992; Westwood, Lawrence, Fleming, \& Tchanturia, 2016).

Regardless of time of onset and aetiology, these deficits - as well as other non-social deficits in central coherence (Lang, Lopez, Stahl, Tchanturia, \& Treasure, 2014) and set-shifting (Westwood, Stahl, Mandy, \& Tchanturia, 2016) - have been commented upon by some as being similar to the 
difficulties seen in autism (Treasure, 2013). Indeed, autism is overrepresented in populations with eating disorders (Huke, Turk, Saeidi, Kent, \& Morgan, 2013; Westwood et al., 2017; Westwood et al., 2015; Westwood, Mandy, \& Tchanturia, 2017), and individuals with an eating disorder score higher on self-report measures of autistic traits (Westwood et al., 2015). Thus, the evidence suggests that autistic-like behaviours, indexed by experimental tasks, self-report measures and clinical behavioural assessments, occur in a sizeable proportion of individuals with AN. While it is unclear to what extent these problems arise due to the effects of malnourishment, autism-related symptoms during development predict reduced treatment efficacy for restrictive eating disorders, potentially indicating a risk factor for relapse (Stewart, McEwen, Konstantellou, Eisler, \& Simic, 2017). Therefore, correctly identifying those individuals who have symptoms of both autism and AN may be important in making decisions about treatment and prognosis.

Alexithymia may play an important role in the heterogeneity of the emotional difficulties and autistic-like difficulties observed in AN. Patients suffering from eating disorders show higher rates of alexithymia (Abbate-Daga, Quaranta, Marzola, Amianto, \& Fassino, 2015; Cochrane, Brewerton, Wilson, \& Hodges, 1993; Westwood, Ker-Gaffney, et al., 2017), in both the starvation phase and after weight gain (Beadle, Paradiso, Salerno, \& McCormick, 2013). Alexithymia has been linked to both eating disorder symptomatology and social difficulties in anorexia (even after depression, anxiety and state of starvation are accounted for; Courty, Godart, Lalanne, \& Berthoz, 2015), and in non-clinical adolescent samples alexithymia is related to eating disorder traits (Karukivi et al., 2010). Emotion recognition deficits may arise in cases of eating disorder where there is co-occurring alexithymia (Brewer, Cook, Cardi, Treasure, \& Bird, 2015), and emerging evidence suggests that alexithymia in AN accounts for the autistic symptoms in some of these individuals (Westwood, KerGaffney, et al., 2017). However, it has also been argued that the association between eating disorders and alexithymia may largely be driven by joint associations with depression (Marchesi, Ossola, Tonna, \& De Panfilis, 2014; Montebarocci, Surcinelli, Rossi, \& Baldaro, 2011); whether this can also account for the association between $\mathrm{AN}$ and autism is unclear. 


\subsection{Aims of the current paper}

Understanding the impact of alexithymia on autism diagnostic measures will yield important insights for both research and clinical practice. Considering the relationship between alexithymia and ADOS scores in populations with and without autism, including populations known to have high rates of alexithymia (e.g. AN) would illuminate whether high alexithymic traits increase ADOS scores. This paper thus examined the association between ADOS scores and alexithymia, using previously collected data from two groups: AN patients, and adolescents with autism or with increased likelihood of showing subthreshold autistic traits due to having a co-twin with autism. The extent to which alexithymia predicted ADOS scores was examined, and our predictions were that individuals with alexithymia would: a) be more likely to meet criteria for an autism/ASD diagnosis; b) score higher on the ADOS than those without alexithymia, and c) score higher on certain ADOS items that tap processes related to alexithymia. To test the latter prediction, in order to avoid an increased risk of Type I error due to multiple comparisons, the decision was made not to examine all items included in the ADOS, but to focus selectively on a subset of items for which previous research predicted an association. These included:

a) Comments on others' emotion

b) Unusual eye contact

c) Facial expressions directed to examiner

d) Communication of own affect (recorded for Module 4 participants only)

e) Insight into typical social situations.

\subsection{Method}

\subsection{ADOS Datasets}


Data from two sources were used in the analyses (participant characteristics are summarised in Table 1). The first was a sample of a patients diagnosed with anorexia nervosa. Patients were adolescent and adult women who undertook the ADOS-2 Module 4. All were either day patients or inpatients (and thus not in disease remission phase). Further details about this sample can be found in Westwood, Mandy and Tchanturia (2017). The second sample consisted of a set of adolescents with autism and their co-twins. This dataset forms part of the Social Relationship Study (SRS), a substudy of the Twins Early Development Study (TEDS) (Haworth, Davis, \& Plomin, 2013). Those assessed with the ADOS in this study represented children originally in the TEDS sample where one or both twin(s) scored above cut-off on the Childhood Autism Spectrum Test (CAST) (Allison et al., 2007; Scott, Baron-Cohen, Bolton, \& Brayne, 2002) or where a parent reported that one or both twin(s) had a diagnosis of ASD. These families then completed the Development and Well-being Assessment (Goodman, Ford, Richards, Gatward, \& Meltzer, 2000), and if one or both twin(s) met the criteria for autism, ASD or Asperger's Syndrome, the family were invited to take part in the SRS. Both twins were assessed with the ADOS-G (ADOS-Generic) and ADI-R (Autism Diagnostic InterviewRevised), and diagnosis confirmed by expert review. Thus, this sample includes adolescents with ASD or subthreshold autistic traits, and their co-twins. Further details about the recruitment and data collection for the SRS population can be found in Colvert et al. (2015). In this analysis, adolescents who were assessed using the ADOS Module 3 were selected, to limit the heterogeneity of the sample (as participants who had completed Modules 2 or 1 were likely to have language or intellectual impairment). We refer to this sample throughout as the SRS sample. 
Table 1: Participant characteristics

\begin{tabular}{|c|c|c|c|}
\hline & & $\begin{array}{l}\text { Anorexia Nervosa }(A N) \\
\text { Sample }(N=96)\end{array}$ & $\begin{array}{l}\text { Social Relationship Study (SRS) } \\
\text { Sample }(N=147)\end{array}$ \\
\hline \multicolumn{2}{|l|}{ Sex } & All female & 43 female, 104 male \\
\hline \multicolumn{2}{|l|}{ Mean Age } & $22.10(13-47)$ & $13.46(12-16)$ \\
\hline \multicolumn{2}{|l|}{ Mean TAS-20 } & $62.40(32-81)$ & $49.03(30-70)$ \\
\hline \multicolumn{2}{|c|}{ Proportion with TAS- $20 \geq 61$} & $61.46 \%$ & $14.29 \%$ \\
\hline \multicolumn{2}{|l|}{ Mean OAS * } & N/A & $17.28(1-37)$ \\
\hline \multirow{2}{*}{$\begin{array}{l}\text { Proportion } \\
\text { meeting ADOS } \\
\text { criteria for: }\end{array}$} & Autism & $19.79 \%$ & $37.41 \%$ \\
\hline & $\begin{array}{l}\text { Autism Spectrum } \\
\text { Disorder }\end{array}$ & $12.50 \%$ & $9.52 \%$ \\
\hline
\end{tabular}

Table 1. Characteristics of the two datasets. Numbers in parentheses represent range. TAS-20 = Toronto Alexithymia Scale; OAS = Observer Alexithymia Scale - Uninsightful Subscale; ADOS = Autism Diagnostic Observation Schedule. The most recent ADOS-2 criteria used to classify cases as autism/autism spectrum disorder were used, for both Module 3 and Module 4. *SRS sample only

\subsection{Alexithymia measures}

The Toronto Alexithymia Scale (TAS-20) is a widely used self-report measure of alexithymic traits, which asks respondents to rate to what extent they struggle to identify and communicate their emotions (Parker et al., 1993). It has previously been used in autistic and eating disorder populations, and its reliability and validity for use in adult autistic populations has been confirmed (Berthoz \& Hill, 2005; Gaigg, Cornell, \& Bird, 2016). Both the SRS sample and AN sample completed the TAS-20; the SRS sample completed a child-friendly version, with a reduced reading age making it more accessible for younger respondents (Rieffe, Oosterveld, \& Terwogt, 2006). Both samples used a 5-point Likert scale to respond to the TAS-20. 
The Observer Alexithymia scale (OAS) (Haviland, Louise Warren, \& Riggs, 2000) is a parent-report measure of alexithymia, containing 5 subscales, including Distant, Uninsightful, Somatizing, Humorless and Rigid scales. The Uninsightful subscale corresponds best to the traits assessed via the TAS-20 (e.g. "Has trouble finding the right words to describe his or her feelings", "Has strong emotions that he or she cannot explain"). These responses were collected using a 5-point Likert scale. Responses to the Uninsightful subscale were available for the SRS sample, but not the AN sample. It is possible that parent-report measures may be advantageous for developing populations who may not yet have developed insight into their own emotional abilities, although it is equally possible that self-report measures are more valid measure of alexithymic difficulties than observerreport measures due to the inherently phenomenological nature of alexithymia. As a result, both the TAS-20 and OAS were used with the SRS sample. The correlation between these two measures of alexithymia was significant, but small: $r_{s}(144)=.19, p=.009$ (one-tailed).

\subsection{Depression and mental health measures}

As alexithymia is highly correlated with symptoms of depression, it is important to consider the possibility that depression, rather than alexithymia, may impact ADOS scores, and that depression may act as a mediating factor between alexithymia and ADOS scores. For the two samples, different measures of depression and mental health were available. For the SRS sample, the parent-report Strengths and Difficulties Questionnaire (Goodman \& Goodman, 2009) was administered, and the Emotional Difficulties subscale was used as a variable to control for internalising problems (anxiety, depression) experienced by this group. For the AN sample, patients completed either the Hospital Anxiety and Depression Scale (HADS; Zigmond \& Snaith, 1983), or the Moods and Feelings Questionnaire (MFQ) (Angold et al., 1995), dependent upon where the participants were recruited from: participants recruited from adult services completed the HADS, and those from Child and Adolescent Eating Disorder Services completed the MFQ. In order to combine scores from all AN participants these measures were converted into z-scores. 


\subsection{Results}

Results for the SRS sample are presented first, followed by the results for the AN sample. For each dataset we examined the impact of alexithymia on meeting criteria for autism or ASD, ADOS scale scores (SA and RRB), and associations with scores on individual ADOS items.

\subsection{SRS sample (autistic adolescents and their co-twins)}

\subsubsection{Does being alexithymic predict meeting diagnostic thresholds on the ADOS?}

We examined whether the two alexithymia measures predicted meeting ASD or autism thresholds on the ADOS. For this sample, the most recent algorithms published in the ADOS-2 were used to determine the groups meeting or not meeting diagnostic cut-offs. Both TAS-20 and OAS scores were entered as categorical variables (TAS-20: cut-off of 61; OAS: median split) in separate logistic regressions to examine whether high scores on these measures predicted whether individuals met ADOS criteria for ASD or autism. Alexithymia group as determined by TAS-20 score was not predictive of meeting cut-offs: Wald $\chi^{2}(1)=0.16, p=.69$ (two-tailed), Nagelkerke R Square $=.001$, OR $=0.83(95 \% \mathrm{Cl}: 0.33,2.10)$. High OAS score was predictive of meeting ADOS criteria: Wald $\chi^{2}(1)$ $=8.86, p=.003$ (two-tailed), Nagelkerke R Square $=.08, \mathrm{OR}=2.81(95 \% \mathrm{Cl}: 1.42,5.54)$. Thus, adolescents scoring above the median OAS score were nearly three times as likely to meet criteria for ASD or autism.

\subsubsection{Are alexithymic traits associated with higher ADOS subscale scores?}

The correlations between the two alexithymia measures and the subscales of the ADOS were examined, summarized in Table 2. As the ADOS subscale scores were skewed (because non-autistic twins generally scored 0, or close to 0), one-tailed Spearman's rank was used. Given the possible effects of depression on alexithymia, correlations with the parent-report SDQ Emotional Difficulties were also examined. 
No significant correlations were found for the TAS-20 (see Table 2), though this measure did correlate significantly with SDQ Emotional Difficulties $\left(r_{s}(145)=.22, p=.004\right)$, with greater selfreported alexithymia being associated with greater parent-reported internalising symptoms. The OAS was moderately correlated with both the SA $\left(r_{s}(144)=.34, p<.001\right)$ and RRB $\left(r_{s}(144)=.31, p\right.$ $<.001)$ scales, and strongly correlated with the SDQ $\left(r_{s}(144)=.51, p<.001\right)$. Given the significant correlations with the SDQ, partial correlations were also conducted, where the SDQ measure was partialled out of the association between alexithymia and ADOS scales. The associations with the OAS were reduced, but remained significant. For SA: $r_{s}(143)=.22, p=.005$. For RRB: $r_{s}(143)=.28$, $p<.001$. 
Table 2: Correlations between ADOS scale scores, alexithymia and internalising symptoms in SRS sample

\begin{tabular}{l|lc|cc}
\hline & \multicolumn{2}{c|}{ First order correlations } & \multicolumn{2}{c}{ Second order correlations } \\
\cline { 2 - 5 } & $\begin{array}{c}\text { TAS-20 } \\
(N=147)\end{array}$ & $\begin{array}{c}\text { OAS } \\
(N=146)\end{array}$ & $\begin{array}{c}\text { TAS-20 } \\
(N=147)\end{array}$ & $\begin{array}{c}\text { OAS } \\
(N=146)\end{array}$ \\
\hline ADOS SA & $r_{s}=.03, p=.38$ & $r_{s}=.34, p<.001^{*}$ & $r_{s}=-.04, p=.60$ & $r_{s}=.22, p=.005^{*}$ \\
\hline ADOS RRB & $r_{s}=.01, p=0.43$ & $r_{s}=.31, p<.001^{*}$ & $r_{s}=-.02, p=.84$ & $r_{s}=.28, p<.001^{*}$ \\
\cline { 1 - 4 } $\begin{array}{l}\text { Internalising } \\
\text { symptoms } \\
\text { (SDQ Emotional } \\
\text { Difficulties) }\end{array}$ & $r_{s}=.22, p=.004 .^{*}$ & $r_{s}=.51, p<.001^{*}$ & & \\
\hline
\end{tabular}

Table 2: Correlations between ADOS scale scores, alexithymia and internalising symptoms, all onetailed. One OAS score was unavailable, these correlations are based on $\mathrm{N}=146$. Second order correlations partial-out the internalising symptoms reported on the Strengths and Difficulties Questionnaire. Asterisks indicate significant correlations. $R R B=$ restricted and repetitive behaviours, SA = Social Affect, TAS-20 = Toronto Alexithymia Scale, OAS = Observer Alexithymia Scale, Uninsightful subscale.

\subsubsection{Are alexithymic traits associated with performance on individual ADOS items?}

The association between alexithymia and scores on individual ADOS items was examined using ordinal regression, in which the scores for items in the ADOS (scored between 0 and 2) were the dependent variables, and alexithymia scores the independent variable. Eye contact was examined using a logistic regression, as scoring this item only allows examiners to rate participants as either "0" or " 2 ". We examined results using both raw scores, and 'standardised' scores which statistically controlled for internalising symptoms given the significant correlations between the alexithymia measures and internalising symptoms. These standardised scores were constructed by regressing alexithymia scores (TAS-20/OAS) onto SDQ Emotional Difficulties scores, and saving the standardised residuals. The resulting variable reflects self- or parent-reported alexithymia after controlling for 
parent-reported internalising symptoms. This approach was used rather than entering both alexithymia and internalising symptoms measures as separate predictors into the regression model due to the problem of collinearity between these two variables. All ordinal regressions met the assumption of proportional odds.

For the raw and standardised TAS-20 regressions, the only ADOS item score that was significantly predicted was social insight (See Table 3). More significant associations emerged for the OAS however (summarized in Table 4). Both raw and standardized OAS score was predictive of eye contact, facial expression, and insight into social situations. For comments on others' emotions/empathy, only raw OAS was a significant predictor.

\begin{tabular}{|l|l|l|l|l|}
\hline \multicolumn{5}{|c|}{ Table 3: Regression results for specific ADOS items for SRS Sample with TAS-20 } \\
\hline \multirow{2}{*}{ ADOS Item } & TAS variable & Wald $\chi^{2}$ (p-value) & $\begin{array}{l}\text { Nagelkerke } \\
\text { Pseudo R-squared }\end{array}$ & Odds Ratio (95\% CIs) \\
\hline Eye Contact & Raw & $0.23, p=.44$ & $<.001$ & $1.00(.097,1.04)$ \\
\cline { 2 - 5 } & Standardised & $0.20, p=.33$ & .01 & $.88(0.51,1.53)$ \\
\hline Facial expression & Raw & $0.82, p=.18$ & .01 & $1.02(0.98,1.05)$ \\
\cline { 2 - 6 } & Standardised & $1.18, p=.14$ & .03 & $0.74(0.44,1.27)$ \\
\hline $\begin{array}{l}\text { Comments on } \\
\text { others } \\
\text { emotions/empathy }\end{array}$ & Raw & $0.20, p=.33$ & .002 & $1.01(0.97,1.04)$ \\
\cline { 2 - 6 } & Standardised & $0.72, p=.20$ & .01 & $1.26(0.74,2.17)$ \\
\hline Social Insight & Raw & $5.42, p=.01$ & .04 & $1.04(1.01,1.08)$ \\
\cline { 2 - 6 } & Standardised & $7.93, p=.003$ & .17 & $2.26(1.28,3.99)$ \\
\hline
\end{tabular}

Table 3: Results from regressions with raw or standardised (controlling for SDQ Emotional Difficulties) TAS-20 scores as a predictor of scores on individual ADOS items. TAS-20 $=$ Toronto Alexithymia Scale. Significance values are all one-tailed. 
Table 4: Regression results for specific ADOS items for SRS Sample with OAS

\begin{tabular}{|l|l|l|l|l|}
\hline ADOS Item & OAS variable & Wald $\chi^{2}(p$-value) & $\begin{array}{l}\text { Nagelkerke } \\
\text { Pseudo R-squared }\end{array}$ & Odds Ratio (95\% Cls) \\
\hline \multirow{2}{*}{ Eye Contact } & Raw & $17.13, p<.001$ & .18 & $1.12,(1.06,1.18)$ \\
\cline { 2 - 5 } & Standardised & $10.93, p<.001$ & .11 & $1.90,(1.30,2.73)$ \\
\hline Facial expression & Raw & $12.04, p<.001$ & .10 & $1.08(1.04,1.13)$ \\
\cline { 2 - 6 } & Standardised & $4.72, p=.02$ & .04 & $1.43(1.04,1.98)$ \\
\hline \multirow{2}{*}{$\begin{array}{l}\text { Comments on } \\
\text { others }\end{array}$} & Rawotions/empathy & $4.66, p=.02$ & .04 & $1.05(1.00,1.09)$ \\
\cline { 2 - 6 } & Standardised & $0.70, p=.20$ & .01 & $1.12(0.84,1.56)$ \\
\hline \multirow{2}{*}{\begin{tabular}{l} 
Social Insight \\
\cline { 2 - 5 }
\end{tabular}} & Raw & $14.77, p<.001$ & .11 & $1.404(1.03,1.93)$ \\
\cline { 2 - 5 } & Standardised & $4.48, p=.02$ & .04 & \\
\hline
\end{tabular}

Table 4: Results from regressions with raw or standardised (controlling for SDQ Emotional Difficulties) OAS-Uninsightful scores as a predictor of scores on individual ADOS items. OAS = Observer Alexithymia Scale-Uninsightful subscale. Significance values are all one-tailed.

\subsection{AN sample (anorexic adults)}

\subsubsection{Does being alexithymic predict meeting diagnostic thresholds on the ADOS?}

We considered whether, in the AN sample, meeting or surpassing the cut-off of 61 on the TAS-20 was predictive of meeting ASD or autism criteria on the ADOS, using a logistic regression. While revised algorithms have been suggested for Module 4 which allow for the calculation of Social Affect and Restricted and Repetitive Behaviours subscales, the most recent version of the ADOS (ADOS-2) did not update the diagnostic thresholds for this Module, and still uses the previous subscales (Social Interaction and Communication). Therefore, these criteria were used to establish which participants were classified as meeting or not meeting criteria, in line with the ADOS-2. Alexithymia was predictive of meeting ADOS criteria: Wald $\chi^{2}=6.64, p=.010$ (two-tailed), Nagelkerke R Square $=.11$, $\mathrm{OR}=3.80(95 \% \mathrm{Cl}: 1.38,10.49) . \mathrm{AN}$ patients with scores in the alexithymic range were thus nearly 4 times as likely to meet the criteria for ASD or autism. 


\subsubsection{Are alexithymic traits associated with higher ADOS subscale scores?}

The correlations between alexithymia and the subscales of the ADOS (calculated using the method outlined in Hus and Lord, 2014) were examined, summarized in Table 5. As for the SRS sample, ADOS subscale scores were skewed and so (one-tailed) Spearman's rank was used. The correlations between the ADOS and alexithymia measures and depression were also considered.

TAS-20 score correlated significantly with SA, though this association was small $\left(r_{s}(94)=.19\right.$, $p=.031)$. TAS-20 scores correlated strongly with self-reported depressive symptoms. Depression was thus partialled out; following this, the association between SA and TAS was no longer significant.

Table 5: Correlations between ADOS scale scores, alexithymia and depression symptoms in AN sample

\begin{tabular}{l|l|l}
\hline & \multicolumn{1}{|c|}{$\begin{array}{c}\text { First order correlations } \\
\text { with TAS-20 } \\
(N=96)\end{array}$} & $\begin{array}{c}\text { Second order correlations } \\
\text { with TAS-20 } \\
(N=93)\end{array}$ \\
\hline ADOS SA & $r_{s}=.19, p=.031^{*}$ & $r_{s}=.09, p=.39$ \\
\hline ADOS RRB & $r_{s}=.09, p=.19$ & $r_{s}=.09, p=.39$ \\
\hline $\begin{array}{l}\text { Depression score } \\
(N=93)\end{array}$ & $r_{s}=.47, p<.001^{*}$ & \\
\hline
\end{tabular}

Table 5: Correlations between alexithymia (TAS-20), ADOS subscale scores and depression measures, all one-tailed. Second order correlations partial-out standardised depression measures. For three participants, measures of depression were not available, thus these correlations are based on $N=93$. Asterisks indicate significant correlations. $\mathrm{RRB}=$ Restricted and Repetitive Behaviours, $\mathrm{SA}=$ Social Affect.

\subsubsection{Are alexithymic traits associated with performance on individual ADOS items?}

As with the SRS sample, the association between alexithymia and scores on individual ADOS items was examined using ordinal regression, with both raw scores and standardised scores controlling for 
depression. Unless otherwise stated, all ordinal regressions met the assumption of proportional odds.

Items' relationships with either raw or standardised TAS-20 scores are summarized in Table 6. Neither raw nor standardised measures were predictive of scores on items measuring eye contact (examined using logistic regression), facial expression, or comments on own emotions. Raw TAS-20 score was not predictive of score on the comments on others' emotions/empathy item. Standardised TAS-20 score was a significant predictor of comments on others' emotions/empathy, but the proportional odds assumption was violated. Two follow-up logistic regressions were run with the scores dichotomized. Only the second, comparing scores of zero or one to two, was significant: Wald $\chi^{2}=5.03, p=.025, \mathrm{OR}=7.22(95 \% \mathrm{Cl}: 1.28,40.50)$. These findings may reflect the fact that alexithymia predicts more severe problems relating to comments on others' emotions / empathy, but does not predict moderate difficulties; however, there were a limited number of individuals with anorexia who scored 2, indicating severe difficulties, on this item $(N=4)$. Raw and standardized TAS20 scores predicted scores on insight into social relationships. 


\begin{tabular}{|c|c|c|c|c|}
\hline \multicolumn{5}{|c|}{ Table 6: Regression results for specific ADOS items for AN Sample } \\
\hline ADOS Item & OAS variable & Wald $\chi^{2}(p$-value) & $\begin{array}{l}\text { Nagelkerke Pseudo } \\
\text { R-squared }\end{array}$ & Odds Ratio (95\% Cls) \\
\hline \multirow[t]{2}{*}{ Eye Contact } & Raw & $1.53, p=.11$ & .02 & $1.02(0.99,1.06)$ \\
\hline & Standardised & $0.04, p=.43$ & .001 & $1.04(0.68,1.59)$ \\
\hline \multirow[t]{2}{*}{ Facial expression } & Raw & $2.40, p=.06$ & .03 & $1.03(0.99,1.07)$ \\
\hline & Standardised & $0.22, p=.32$ & .003 & $1.10(0.73,1.66)$ \\
\hline \multirow{2}{*}{$\begin{array}{l}\text { Comments on own } \\
\text { emotion }\end{array}$} & Raw & $2.43, p=.06$ & .04 & $1.03(0.99,1.08)$ \\
\hline & Standardised & $0.32, p=.29$ & .01 & $1.14(0.72,1.81)$ \\
\hline \multirow{2}{*}{$\begin{array}{l}\text { Comments on } \\
\text { others } \\
\text { emotions/empathy }\end{array}$} & Raw & $0.71, p=.20$ & .01 & $1.02(0.98,1.06)$ \\
\hline & Standardised & $4.51, p=.02$ & .06 & $1.71(1.04,2.80)$ \\
\hline \multirow[t]{2}{*}{ Social Insight } & Raw & $5.10, p=.01$ & .07 & $1.05(1.01,1.09)$ \\
\hline & Standardised & $4.00, p=.02$ & .06 & $1.58(1.01,2.46)$ \\
\hline
\end{tabular}

Table 6: Results from regressions with raw or standardised (controlling for depression) TAS scores as a predictor of scores on individual ADOS items. Significance values are all one-tailed.

\subsection{Discussion}

This paper provides a first examination of the relationship between alexithymia and ratings on a standardised diagnostic instrument for autism. This relationship was examined in a sample of adolescents who were autistic or at genetic risk for autism, and a sample of patients with anorexia, a condition in which alexithymia is also prevalent and in which rates of autism are increased with respect to the general population. While alexithymia predicted the likelihood of meeting diagnostic criteria for autism for both groups, different patterns of results emerged for the two groups with respect to ADOS scores. For the autistic adolescents and their co-twins, associations between parent-reported alexithymia and ADOS measures were found at all levels of analysis. This included 
alexithymia predicting the likelihood of meeting diagnostic cut-off, increased scores on the SA and RRB subscales, and scores on pre-selected ADOS items. For the AN group, self-reported alexithymia predicted the likelihood of meeting diagnostic cut-off, was correlated with the social affect subscale score, and predicted scores on ADOS items commenting on others' emotions/empathy and social insight. The finding that co-occurring alexithymia predicts the likelihood of patients with anorexia scoring above diagnostic cut-off suggests that co-occurring alexithymia may be a potential explanation for the high proportion of patients with AN who exhibit symptoms of ASD.

Two features of the results complicate the relationship between alexithymia and ADOS scores; the differential relationship between ADOS scores and parent- and child-reported alexithymia in the SRS sample, and the different pattern of correlations between scores on specific ADOS items and alexithymia scores in the SRS and AN samples.

With respect to the first issue, it is important to note that although the OAS and the ADOS are both observer-rated measures, they are completed by different observers. Parents complete the OAS while trained researchers administer and score the ADOS. Thus, it seems unlikely that the positive findings for the OAS but not the TAS for the SRS sample are due to an effect of observer bias, as the two measures relied on different observers. The differential predictive ability of the self- and parentreport alexithymia measures in the SRS sample are in keeping with other reports suggesting that self-reported alexithymia measures may be problematic for children. In the current sample there was only a small correlation between the OAS and TAS-20. Similarly, Griffin and colleagues (2016) did not find a significant correlation between their child self-report and parent-report measures of alexithymia, although it should be noted that the sample used by Griffin et al. was much smaller $(N=56)$ than the adolescent autistic sample tested here, and also younger ( 8 to 13 years). These results do not necessarily suggest that parent-report is more veridical than self-report data when measuring alexithymia in childhood. Rather, the results show that a trained rater's judgement of adolescents' autism symptomology is better predicted by parents' judgements of level of alexithymic 
traits than by self-reported levels of alexithymia. Nonetheless, the discrepancy between self and parent-rated alexithymia in children warrants further study.

With respect to the second issue, the AN group were included to examine the relationship between alexithymia and ADOS scores in a second population in which alexithymia and autistic symptoms are prevalent. Fewer associations between ADOS items and alexithymia were found for this group than for the SRS sample. Several potential reasons for why this occurred can be ruled out. First, as a group, the anorexia patients rated themselves as highly alexithymic, with the majority of patients surpassing the TAS-20 cut-off. Thus, it seems unlikely that few associations emerged because anorexic patients were not aware of their emotional difficulties. However, it is possible that scores may have been inflated, at least in some individuals, by low self-esteem which may produce negative biases on any self-report measure relating to impaired functioning. Although controlling for depression may account for some of this potential effect, depression is an imperfect measure of selfesteem.

Second, given the lack of significant associations between self-report alexithymia and ADOS scores in the SRS sample, perhaps an observer measure of alexithymia would have been associated with more ADOS scores in the AN sample, had they been available. However, previous studies have found significant correlations between self- and observer-reported alexithymia in eating disorder populations (Berthoz, Perdereau, Godart, Corcos, \& Haviland, 2007), which would suggest that we may not have seen the same discrepancy observed for the SRS sample, even if observer-report data had been available.

Finally, all of the AN group were inpatients, while the SRS sample included some individuals who, while at higher genetic risk of autism symptoms due to their twin being high in autistic symptoms, were not autistic, nor suffering from any psychiatric condition. Arguably this may be expected to lead to an increased range of ADOS scores in the SRS sample, which may have allowed associations to emerge for this group only. However, the range and standard deviations of ADOS scores was 
similar between the two samples (although it should be noted that they undertook different ADOS modules). Increased range of ADOS scores therefore cannot explain why greater associations emerged for the SRS sample.

While the above suggestions thus appear unlikely to be able to explain the current findings, differences in results between these two groups could potentially be due to differences in gender and age: the AN group was exclusively female, and included adults as well as adolescents, while the SRS sample included predominantly male adolescents aged up to 16 years. Both age and gender have been shown to be related to levels of alexithymic traits, and meta-analytic analyses suggest that gender differences in the prevalence of alexithymia change from adolescence to adulthood; males score higher than females on measures of alexithymia in adulthood (Levant, Hall, Williams, \& Hasan, 2009), while in adolescence this pattern is reversed (Honkalampi et al., 2009; Joukamaa et al., 2007). Overall, the prevalence of alexithymia increases during adolescence, with a decrease and stabilisation of alexithymia prevalence observed in late adolescence (Murphy, Brewer, Catmur \& Bird, 2017). Future studies should ideally match samples on age and gender to differentiate the impact of diagnostic group and sample demographics.

Although this paper has focused on the impact of alexithymia on the ADOS assessment specifically, other assessment tools used to diagnose autism are also likely to be affected by alexithymia. Indeed, these results raise the question as to whether the diagnostic criteria for autism itself need to be revised such that they do not include those symptoms which might be a product of co-occurring alexithymia rather than autism itself, and therefore present in only approximately $50 \%$ of the autistic population. More broadly, as well as the potential impact on diagnosis, alexithymia is a risk factor for a number of other mental health conditions, and has recently been shown to mediate between autism symptoms and anxiety (Maisel et al., 2016). Knowing whether an individual presents with alexithymia may guide clinicians in their decisions about what other support a recently diagnosed individual with autism might need. Being able to disentangle symptoms of autism from symptoms of 
alexithymia is therefore an important part of the diagnostic process, and one that will need to be given careful thought in future research, as current measures of autism traits overlap with measures of alexithymia. The results also highlight the need to assess the impact of alexithymia in other groups, and for conditions other than autism.

\subsection{Summary}

This paper is the first to examine the impact of alexithymia on ADOS assessments. Using data from autistic adolescents and their co-twins, and an eating disorder population, we examined the extent to which alexithymia predicted meeting the diagnostic threshold for autism, whether alexithymia correlated with ADOS scores, and whether alexithymia predicted individual item scores. Alexithymia predicted ADOS scores in both groups, although to a greater degree in the group of autistic adolescents and their co-twins. Interestingly, within this group, parent-reported alexithymia was more predictive of ADOS scores than self-report data. These findings have implications for research practices that rely on the ADOS to establish diagnosis in research participants, and suggest the need for more controlled investigations into the impact of alexithymia on autism diagnostic practices.

\subsection{References}

Abbate-Daga, G., Quaranta, M., Marzola, E., Amianto, F., \& Fassino, S. (2015). The relationship between alexithymia and intolerance of uncertainty in anorexia nervosa. Psychopathology, 48(3), 202-208. http://doi.org/10.1159/000381587

Allison, C., Williams, J., Scott, F., Stott, C., Bolton, P., Baron-Cohen, S., \& Brayne, C. (2007). The Childhood Asperger Syndrome Test (CAST): Test-retest reliability in a high scoring sample. Autism, 11(2), 173-185. http://doi.org/10.1177/1362361307075710

Angold, A., Costello, E. J., Messer, S. C., Pickles, A., Winder, F., \& Silver, D. (1995). The development of a short questionnaire for use in epidemiological studies of depression in children and adolescents. International Journal of Methods in Psychiatric Research. http://doi.org/1049- 
$8931 / 95 / 040251-12$

Bastiaansen, J. A., Meffert, H., Hein, S., Huizinga, P., Ketelaars, C., Pijnenborg, M., ... De Bildt, A. (2011). Diagnosing autism spectrum disorders in adults: The use of Autism Diagnostic Observation Schedule (ADOS) module 4. Journal of Autism and Developmental Disorders, 41(9), 1256-1266. http://doi.org/10.1007/s10803-010-1157-x

Beadle, J. N., Paradiso, S., Salerno, A., \& McCormick, L. M. (2013). Alexithymia, emotional empathy, and self-regulation in anorexia nervosa. Annals of Clinical Psychiatry, 25(2), 107-120.

Berthoz, S., \& Hill, E. L. (2005). The validity of using self-reports to assess emotion regulation abilities in adults with autism spectrum disorder. European Psychiatry, 20(3), 291-298. http://doi.org/10.1016/j.eurpsy.2004.06.013

Berthoz, S., Lalanne, C., Crane, L., \& Hill, E. L. (2013). Investigating emotional impairments in adults with autism spectrum disorders and the broader autism phenotype. Psychiatry Research, 208(3), 257-264. http://doi.org/10.1016/j.psychres.2013.05.014

Berthoz, S., Perdereau, F., Godart, N., Corcos, M., \& Haviland, M. G. (2007). Observer- and self-rated alexithymia in eating disorder patients: Levels and correspondence among three measures. Journal of Psychosomatic Research, 62(3), 341-347. http://doi.org/10.1016/j.jpsychores.2006.10.008

Bird, G., \& Cook, R. (2013). Mixed emotions: the contribution of alexithymia to the emotional symptoms of autism. Translational Psychiatry, 3(7), e285. http://doi.org/10.1038/tp.2013.61

Bird, G., Press, C., \& Richardson, D. C. (2011). The role of alexithymia in reduced eye-fixation in autism spectrum conditions. Journal of Autism and Developmental Disorders, 41(11), 15561564. http://doi.org/10.1007/s10803-011-1183-3

Bird, G., Silani, G., Brindley, R., White, S., Frith, U., \& Singer, T. (2010). Empathic brain responses in insula are modulated by levels of alexithymia but not autism. Brain, 133(5), 1515-1525. 
Brewer, R., Biotti, F., Catmur, C., Press, C., Happé, F., Cook, R., \& Bird, G. (2016). Can neurotypical individuals read autistic facial expressions? Atypical production of emotional facial expressions in autism spectrum disorders. Autism Research, 9(2), 262-271.

Brewer, R., Collins, F., Cook, R., \& Bird, G. (2015). Atypical Trait Inferences From Facial Cues in Alexithymia. Emotion, 15(5), 637-643. http://doi.org/10.1037/emo0000066

Brewer, R., Cook, R., \& Bird, G. (2016). Alexithymia: A general deficit of interoception. Royal Society Open Science, 3(150664).

Brewer, R., Cook, R., Cardi, V., Treasure, J., \& Bird, G. (2015). Emotion recognition deficits in eating disorders are explained by co-occurring alexithymia. Royal Society Open Science, 2(1), 140382140382. http://doi.org/10.1098/rsos.140382

Cochrane, C. E., Brewerton, T. D., Wilson, D. B., \& Hodges, E. L. (1993). Alexithymia in the eating disorders. International Journal of Eating Disorders, 14(2), 219-222.

http://doi.org/10.1002/1098-108X(199309)14:2<219::AID-EAT2260140212>3.0.CO;2-G

Coll, M. P., Viding, E., Rütgen, M., Silani, G., Lamm, C., Catmur, C., \& Bird, G. (2017). are we really measuring empathy? Proposal for a new measurement framework. Neuroscience \& Biobehavioral Reviews.

Colvert, E., Tick, B., McEwen, F., Stewart, C., Curran, S. R., Woodhouse, E., ... Bolton, P. (2015). Heritability of Autism Spectrum Disorder in a UK Population-Based Twin Sample. JAMA Psychiatry, 72(5), 415-23. http://doi.org/10.1001/jamapsychiatry.2014.3028

Cook, R., Brewer, R., Shah, P., \& Bird, G. (2013). Alexithymia, not autism, predicts poor recognition of emotional facial expressions. Psychological Science, 24(5), 723-732.

Courty, A., Godart, N., Lalanne, C., \& Berthoz, S. (2015). Alexithymia, a compounding factor for eating and social avoidance symptoms in anorexia nervosa. Comprehensive Psychiatry, 56, 217-228. http://doi.org/10.1016/j.comppsych.2014.09.011 
Falkmer, T., Anderson, K., Falkmer, M., \& Horlin, C. (2013). Diagnostic procedures in autism spectrum disorders: A systematic literature review. European Child and Adolescent Psychiatry, 22(6), 329-340. http://doi.org/10.1007/s00787-013-0375-0

Foulkes, L., Bird, G., Gökçen, E., McCrory, E., \& Viding, E. (2015). Common and distinct impacts of autistic traits and alexithymia on social reward. PLOS ONE, 10(4), 1-12. http://doi.org/10.1371/journal.pone.0121018

Franz, M., Popp, K., Schaefer, R., Sitte, W., Schneider, C., Hardt, J., ... Braehler, E. (2008). Alexithymia in the German general population. Social Psychiatry and Psychiatric Epidemiology, 43(1), 5462. http://doi.org/10.1007/s00127-007-0265-1

Gaigg, S. B., Cornell, A. S., \& Bird, G. (2016). The psychophysiological mechanisms of alexithymia in autism spectrum disorder. Autism, 1362361316667062.

Gillberg, C., \& Råstam, M. (1992). Do some cases of anorexia nervosa reflect underlying autistic-like conditions? Behavioural Neurology, 5(1), 27-32. http://doi.org/10.3233/BEN-1992-5105

Goodman, A., \& Goodman, R. (2009). Strengths and Difficulties Questionnaire as a Dimensional Measure of Child Mental Health. Journal of the American Academy of Child \& Adolescent Psychiatry, 48(4), 400-403. http://doi.org/10.1097/CHI.0b013e3181985068

Goodman, R., Ford, T., Richards, H., Gatward, R., \& Meltzer, H. (2000). The Development and WellBeing Assessment: description and initial validation of an integrated assessment of child and adolescent psychopathology. Journal of Child Psychology and Psychiatry, 41(5), 645-655. http://doi.org/10.1111/j.1469-7610.2000.tb02345.x

Gotham, K., Risi, S., Pickles, A., \& Lord, C. (2007). The autism diagnostic observation schedule: Revised algorithms for improved diagnostic validity. Journal of Autism and Developmental Disorders, 37(4), 613-627. http://doi.org/10.1007/s10803-006-0280-1

Griffin, C., Lombardo, M. V., \& Auyeung, B. (2016). Alexithymia in children with and without autism 
spectrum disorders. Autism Research, 9(7), 773-780. http://doi.org/10.1002/aur.1569

Grynberg, D., Chang, B., Corneille, O., Maurage, P., Vermeulen, N., Berthoz, S., \& Luminet, O. (2012). Alexithymia and the processing of emotional facial expressions (EFEs): Systematic review, unanswered questions and further perspectives. PLOS ONE, 7(8). http://doi.org/10.1371/journal.pone.0042429

Grynberg, D., Luminet, O., Corneille, O., Grèzes, J., \& Berthoz, S. (2010). Alexithymia in the interpersonal domain: A general deficit of empathy? Personality and Individual Differences, 49(8), 845-850. http://doi.org/10.1016/j.paid.2010.07.013

Guttman, H., \& Laporte, L. (2002). Alexithymia, empathy, and psychological symptoms in a family context. Comprehensive Psychiatry, 43(6), 448-455. http://doi.org/10.1053/comp.2002.35905

Haviland, M. G., Louise Warren, W., \& Riggs, M. L. (2000). An Observer Scale to Measure Alexithymia. Psychosomatics, 41(5), 385-392. http://doi.org/10.1176/appi.psy.41.5.385

Haworth, C. M. A., Davis, O. S. P., \& Plomin, R. (2013). Twins Early Development Study (TEDS): A Genetically Sensitive Investigation of Cognitive and Behavioral Development From Childhood to Young Adulthood. Twin Research and Human Genetics: The Official Journal of the International Society for Twin Studies, 16(1), 10.1017/thg.2012.91. http://doi.org/10.1017/thg.2012.91

Heaton, P., Reichenbacher, L., Sauter, D. A., Allen, R., Scott, S., \& Hill, E. (2012). Measuring the effects of alexithymia on perception of emotional vocalizations in autistic spectrum disorder and typical development. Psychological Medicine, 42(11), 2453-2459.

http://doi.org/10.1017/S0033291712000621

Hill, E., Berthoz, S., \& Frith, U. (2004). Brief report: Cognitive processing of own emotions in individuals with autistic spectrum disorder and in their relatives. Journal of Autism and Developmental Disorders, 34(2), 229-235.

http://doi.org/10.1023/B:JADD.0000022613.41399.14 
Honkalampi, K., Tolmunen, T., Hintikka, J., Rissanen, M. L., Kylmä, J., \& Laukkanen, E. (2009). The prevalence of alexithymia and its relationship with Youth Self-Report problem scales among Finnish adolescents. Comprehensive psychiatry, 50(3), 263-268.

Huke, V., Turk, J., Saeidi, S., Kent, A., \& Morgan, J. F. (2013). Autism spectrum disorders in eating disorder populations: A systematic review. European Eating Disorders Review, 21(5), 345-351. http://doi.org/10.1002/erv.2244

Humphreys, T. P., Wood, L. M., \& Parker, J. D. A. (2009). Alexithymia and satisfaction in intimate relationships. Personality and Individual Differences, 46(1), 43-47. http://doi.org/10.1016/j.paid.2008.09.002

Hus, V., \& Lord, C. (2014). The Autism Diagnostic Observation Schedule, Module 4: Revised Algorithm and Standardized Severity Scores. Journal of Autism and Developmental Disorders, 44(8), 1996-2012. http://doi.org/10.1021/nl061786n.Core-Shell

Jongen, S., Axmacher, N., Kremers, N. A. W., Hoffmann, H., Limbrecht-Ecklundt, K., Traue, H. C., \& Kessler, H. (2014). An investigation of facial emotion recognition impairments in alexithymia and its neural correlates. Behavioural Brain Research, 271, 129-139. http://doi.org/10.1016/j.bbr.2014.05.069

Joukamaa, M., Taanila, A., Miettunen, J., Karvonen, J. T., Koskinen, M., \& Veijola, J. (2007). Epidemiology of alexithymia among adolescents. Journal of Psychosomatic Research, 63(4), 373-376.

Kano, M., Hamaguchi, T., Itoh, M., Yanai, K., \& Fukudo, S. (2007). Correlation between alexithymia and hypersensitivity to visceral stimulation in human. Pain, 132(3), 252-263. http://doi.org/10.1016/j.pain.2007.01.032

Karukivi, M., Hautala, L., Korpelainen, J., Haapasalo-Pesu, K.-M., Liuksila, P.-R., Joukamaa, M., \& Saarijarvi, S. (2010). Alexithymia and eating disorder symptoms in adolescents. Eating 
Disorders, 18(3), 226-238. http://doi.org/10.1080/10640261003719518

Kenny, L., Hattersley, C., Molins, B., Buckley, C., Povey, C., \& Pellicano, E. (2016). Which terms should be used to describe autism? Perspectives from the UK autism community. Autism, 20(4), 442462. http://doi.org/10.1177/1362361315588200

Kranzler, A., Young, J. F., Hankin, B. L., Abela, J. R. Z., Elias, M. J. E., \& Selby, E. A. (2016). Emotional awareness: a transdiagnostic risk factor for internalizing symptoms in children and adolescents? Journal of Clinical Child and Adolescent Psychology, 45(3), 262-269. http://doi.org/10.1080/15374416.2014.987379

Kring, A. M. (2008). Emotion Disturbances as Transdiagnostic Processes in Psychopathology. In M. Lewis, J. M. Haviland-Jones, \& L. F. Barrett (Eds.), Handbook of Emotions (Third, pp. 691-709). New York, London: The Guildford Press. http://doi.org/10.2307/2076468

Kucharska-Pietura, K., Nikolaou, V., Masiak, M., \& Treasure, J. (2004). The Recognition of Emotion in the Faces and Voice of Anorexia Nervosa. International Journal of Eating Disorders, 35(1), 4247. http://doi.org/10.1002/eat.10219

Lang, K., Lopez, C., Stahl, D., Tchanturia, K., \& Treasure, J. (2014). Central coherence in eating disorders: An updated systematic review and meta-analysis. The World Journal of Biological Psychiatry: The Official Journal of the World Federation of Societies of Biological Psychiatry, 2975(JUNE), 1-13. http://doi.org/10.3109/15622975.2014.909606

Levant, R. F., Hall, R. J., Williams, C. M., \& Hasan, N. T. (2009). Gender differences in alexithymia. Psychology of men \& masculinity, 10(3), 190.

Liss, M., Mailloux, J., \& Erchull, M. J. (2008). The relationships between sensory processing sensitivity, alexithymia, autism, depression, and anxiety. Personality and Individual Differences, 45(3), 255-259. http://doi.org/10.1016/j.paid.2008.04.009

Maisel, M. E., Stephenson, K. G., South, M., Rodgers, J., Freeston, M. H., \& Gaigg, S. B. (2016). 
Modeling the Cognitive Mechanisms Linking Autism Symptoms and Anxiety in Adults. Journal of Abnormal Psychology, 125(5), No Pagination Specified. http://doi.org/10.1037/abn0000168

Marchesi, C., Brusamonti, E., \& Maggini, C. (2000). Are alexithymia, depression, and anxiety distinct constructs in affective disorders? Journal of Psychosomatic Research, 49(1), 43-49. http://doi.org/10.1016/S0022-3999(00)00084-2

Marchesi, C., Ossola, P., Tonna, M., \& De Panfilis, C. (2014). The TAS-20 more likely measures negative affects rather than alexithymia itself in patients with major depression, panic disorder, eating disorders and substance use disorders. Comprehensive Psychiatry, 55(4), 972-978. http://doi.org/10.1016/j.comppsych.2013.12.008

McDonald, P. W., \& Prkachin, K. M. (1990). The expression and perception of facial emotion in alexithymia: a pilot study. Psychosomatic Medicine, 52(2), 199-210. http://doi.org/10.1097/00006842-199003000-00007

Milosavljevic, B., Carter Leno, V., Simonoff, E., Baird, G., Pickles, A., Jones, C. R. G., ... Happé, F. (2016). Alexithymia in Adolescents with Autism Spectrum Disorder: Its Relationship to Internalising Difficulties, Sensory Modulation and Social Cognition. Journal of Autism and Developmental Disorders, 46(4), 1354-1367. http://doi.org/10.1007/s10803-015-2670-8

Montebarocci, O., Surcinelli, P., Rossi, N., \& Baldaro, B. (2011). Alexithymia, verbal ability and emotion recognition. Psychiatric Quarterly, 82(3), 245-252. http://doi.org/10.1007/s11126010-9166-7

Moriguchi, Y., Decety, J., Ohnishi, T., Maeda, M., Mori, T., Nemoto, K., ... Komaki, G. (2007). Empathy and judging other's pain: An fMRI study of alexithymia. Cerebral Cortex, 17(9), 2223-2234. http://doi.org/10.1093/cercor/bhl130

Morris, R., Bramham, J., Smith, E., \& Tchanturia, K. (2014). Empathy and social functioning in anorexia nervosa before and after recovery. Cognitive Neuropsychiatry, 19(1), 47-57. 
http://doi.org/10.1080/13546805.2013.794723

Murphy, J., Brewer, R., Catmur, C., \& Bird, G. (2017). Interoception and psychopathology: A developmental neuroscience perspective. Developmental cognitive neuroscience, 23, 45-56.

Nyklíček, I., \& Vingerhoets, A. J. J. M. (2000). Alexithymia is associated with low tolerance to experimental painful stimulation. Pain, 85(3), 471-475. http://doi.org/10.1016/S03043959(99)00295-X

Oakley, B. F. M., Brewer, R., Bird, G., \& Catmur, C. (2016). Theory of Mind Is Not Theory of Emotion: A Cautionary Note on the Reading the Mind in the Eyes Test. Journal of Abnormal Psychology, 125(6), 818-23. http://doi.org/10.1037/abn0000182

Ogrodniczuk, J. S., Piper, W. E., \& Joyce, A. S. (2011). Effect of alexithymia on the process and outcome of psychotherapy: A programmatic review. Psychiatry Research, 190(1), 43-48. http://doi.org/10.1016/j.psychres.2010.04.026

Parker, J. D., Bagby, R. M., Taylor, G. J., Endler, N. S., \& Schmitz, P. (1993). Factorial validity of the 20item Toronto Alexithymia Scale. European Journal of Personality, 7(4), 221-232. http://doi.org/10.1002/per.2410070403

Pinard, L., Negrete, J. C., Annable, L., \& Audet, N. (1996). Alexithymia in Substance Abusers. The American Journal on Addictions, 5(May), 32-39. http://doi.org/doi: 10.1111/j.15210391.1996.tb00281.x

Rieffe, C., Oosterveld, P., \& Terwogt, M. M. (2006). An alexithymia questionnaire for children: Factorial and concurrent validation results. Personality and Individual Differences, 40(1), 123133. http://doi.org/10.1016/j.paid.2005.05.013

Russell, T. A., Schmidt, U., Doherty, L., Young, V., \& Tchanturia, K. (2009). Aspects of social cognition in anorexia nervosa: Affective and cognitive theory of mind. Psychiatry Research, 168(3), 181185. http://doi.org/10.1016/j.psychres.2008.10.028 
Schmidt, U., Jiwany, A., \& Treasure, J. (1993). A controlled study of alexithymia in eating disorders. Comprehensive Psychiatry, 34(1), 54-58. http://doi.org/10.1016/0010-440X(93)90036-4

Scott, F., Baron-Cohen, S., Bolton, P., \& Brayne, C. (2002). The CAST (Childhood Asperger Syndrome Test). Autism, 6(1), 9-31. http://doi.org/10.1177/1362361305049029

Sivik, T. (1993). Alexithymia and hypersensitivity to touch and palpation. Integrative physiological and behavioral science, 28(2), 130-136.

Spitzer, C., Siebel-Jürges, U., Barnow, S., Grabe, H. J., \& Freyberger, H. J. (2005). Alexithymia and Interpersonal Problems. Psychotherapy and Psychosomatics, 74(4), 240-246. http://doi.org/10.1159/000085148

Stewart, M. E., Barnard, L., Pearson, J., Hasan, R., \& O’Brien, G. (2006). Presentation of depression in autism and Asperger syndrome: A review. Autism, 10(1), 103-116. http://doi.org/10.1177/1362361306062013

Stewart, C.S., McEwen, F.S., Konstantellou, A., Eisler, I., Simic, M. (2017). Impact of ASD Traits on Treatment Outcomes of Eating Disorders in Girls. European Eating Disorders Review. 25:2, 123-128. DOI: $10.1002 /$ erv.2497

Stone, W. S., \& Iguchi, L. (2011). Do Apparent Overlaps between Schizophrenia and Autistic Spectrum Disorders Reflect Superficial Similarities or Etiological Commonalities? North American Journal of Medicine \& Science, 4(3), 124-133. http://doi.org/10.7156/v4i3p124

Sturm, V. E., \& Levenson, R. W. (2011). Alexithymia in neurodegenerative disease. Neurocase, 17(3), 242-50. http://doi.org/10.1080/13554794.2010.532503

Tchanturia, K., Happé, F., Godley, J., Treasure, J., Bara-Carril, N., \& Schmidt, U. (2004). “Theory of Mind" in Anorexia Nervosa. European Eating Disorder Review, 12, 361-366. Retrieved from http://www.ncbi.nlm.nih.gov/pubmed/21502668 
Treasure, J. (2013). Coherence and other autistic spectrum traits and eating disorders: Building from mechanism to treatment. The Birgit Olsson lecture. Nordic Journal of Psychiatry, 67(1), 38-42. http://doi.org/10.3109/08039488.2012.674554

Trevisan, D. A., Bowering, M., \& Birmingham, E. (2016). Alexithymia, but not autism spectrum disorder, may be related to the production of emotional facial expressions. Mol Autism, 7, 46. http://doi.org/10.1186/s13229-016-0108-6

van 't Wout, M., Aleman, A., Bermond, B., \& Kahn, R. S. (2007). No words for feelings: alexithymia in schizophrenia patients and first-degree relatives. Comprehensive Psychiatry, 48(1), 27-33. http://doi.org/10.1016/j.comppsych.2006.07.003

Vanheule, S., Desmet, M., Meganck, R., \& Bogaerts, S. (2007). Alexithymia and Interpersonal Problems. Journal of Clinical Psychology, 63(1), 109-117. http://doi.org/10.1002/jclp

Westwood, H., Eisler, I., Mandy, W., Leppanen, J., Treasure, J., \& Tchanturia, K. (2015). Using the Autism-Spectrum Quotient to Measure Autistic Traits in Anorexia Nervosa: A Systematic Review and Meta-Analysis. Journal of Autism and Developmental Disorders. http://doi.org/10.1007/s10803-015-2641-0

Westwood, H., Kerr-Gaffney, J., Stahl, D., \& Tchanturia, K. (2017). Alexithymia in eating disorders: Systematic review and meta-analyses of studies using the Toronto Alexithymia Scale. Journal of Psychosomatic Research, 99(March), 66-81. http://doi.org/10.1016/j.jpsychores.2017.06.007

Westwood, H., Lawrence, V., Fleming, C., \& Tchanturia, K. (2016). Exploration of friendship experiences, before and after illness onset in females with anorexia nervosa: A qualitative study. PLoS ONE, 11(9), 1-16. http://doi.org/10.1371/journal.pone.0163528

Westwood, H., Mandy, W., \& Tchanturia, K. (2017). Clinical evaluation of autistic symptoms in women with anorexia nervosa. Molecular Autism, 8(1), 12. http://doi.org/10.1186/s13229-0170128-x 
Westwood, H., Stahl, D., Mandy, W., \& Tchanturia, K. (2016). The set-shifting profiles of anorexia nervosa and autism spectrum disorder using the Wisconsin Card Sorting Test: a systematic review and meta-analysis. Psychological Medicine, 46(9), 1809-1827. http://doi.org/10.1017/S0033291716000581

Westwood, H., \& Tchanturia, K. (2017). Autism Spectrum Disorder in Anorexia Nervosa: An Updated Literature Review. Current Psychiatry Reports, 19(7). http://doi.org/10.1007/s11920-017-07919

Wood, R. L., \& Williams, C. (2007). Neuropsychological correlates of organic alexithymia. Journal of the International Neuropsychological Society : JINS, 13(3), 471-479. http://doi.org/10.1017/S1355617707070518

Wotschack, C., \& Klann-Delius, G. (2013). Alexithymia and the conceptualization of emotions: A study of language use and semantic knowledge. Journal of Research in Personality, 47(5), 514523. http://doi.org/10.1016/j.jrp.2013.01.011

Zigmond, A. S., \& Snaith, R. P. (1983). The Hospital Anxiety and Depression Scale. Acta Psychiatrica Scandinavica, 67(6), 361-370. http://doi.org/10.1111/j.1600-0447.1983.tb09716.x

Zonneville-Bendeck, M. J. S., van Goozen, P. T., Cohen-Kettenis, P. T., van Elburg, A., \& van Engeland, H. (2002). Do adolescent anorexia nervosa patients have deficits in emotional functioning? European Child \& Adolescent Psychiatry, 11, 38-42. 